\title{
Management Strategies for Enhancing Students' Entrepreneurship in Industrial and Community Education Colleges of the Northeastern Thailand
}

\author{
Pha Agsonsua ${ }^{1}$, Prayuth Chusorn, ${ }^{1,}$, Vanit Prasertporn ${ }^{1}$, Adul Pimtong ${ }^{2} \&$ Natthasak Samranruen ${ }^{2}$ \\ ${ }^{1}$ Faculty of Education, Northeastern University, Khon Kaen Province, Thailand \\ ${ }^{2}$ Industrial and Community Education College, Thailand \\ *Correspondence: Faculty of Education, Northeastern University, Khon Kaen Province, Thailand. E-mail: \\ prayuth.chu@neu.ac.th
}

Received: July 14, 2020

doi:10.5430/wje.v10n6p143
Accepted: October 28, $2020 \quad$ Online Published: December 20, 2020

URL: https://doi.org/10.5430/wje.v10n6p143

\begin{abstract}
The objectives of this research were to study the needs assessment and to develop management strategies for enhancing the entrepreneurship of students. This study was conducted by utilizing Mixed Methods Research. The sample group used in this study consisted of School Directors and Teachers totaling 226 persons under the Northeastern Industrial and Community Education Colleges in Thailand. The tools used for data collection were questionnaires and strategic evaluation forms. Data were analyzed through descriptive statistics, namely, frequency distributions, percentages, means, standard deviations, and PNI Modified.The results of the research revealed the followings: 1)In all, the current conditions of management for enhancing the entrepreneurship of the students were at a "High" level. Regarding the desired conditions, it was, in general, at the "Highest" level. As for the needs priority, it was found that the most needed aspects were the characteristics of Entrepreneurship, the management of an 'Entrepreneurial Incubation Center, and Teacher Development, respectively. 2) The management strategies for enhancing the entrepreneurship of students comprised visions, missions, targets, of 9 strategies with 62 measures, and 67 indicators. Some recommendations and suggestions for future research were introduced.
\end{abstract}

Keywords: management strategies, entrepreneur, community college

\section{Introduction}

Education in the $21^{\text {st }}$ Century focuses on the fact that we are in a period of rapid changes taking place in a global environment in which many countries are increasingly interconnected. The education system needs to be adjusted to meet the needs of the youth, society, and the labor market, both for the present and the future. Thai policy makers and educational personnel should focus on preparing young people and equipping them with the necessary skills required to live their lives in society in the future. In the last two decades, Thailand undertook educational reforms in order to improve the quality of education. However, a great majority of students still simply do not have the basic skills they need. This can be seen from the evaluation results at both the national and international levels. In addition, the ratio of children, who do not continue on to pursue a secondary education, is still creating a condition in which many youth still lack the necessary skills to work in the real world. With respect to achieving its 20-year national strategic plan, improvement of the educational system and skills development are important issues for Thailand.Moreover, there is the need to increase potential, opportunity, and economic equity within the country. Nevertheless, due to the fact that Thailand tends to be an aging society and that there is a decrease in the proportion of working-age populations, Thailand is becoming deficient in skilled human resources, which is an important factor in creating Thailand's future competitiveness. Therefore, the quality of the education system, as well as the competencies and skills of graduates, are the keys to solve the problem. Although there are educational and development strategies and reforms, which are taking place in the educational system in Thailand and which are aimed at responding to the problems mentioned above, the challenges presently being faced in Thailand are: 1) how to make the desired changes happen in the classrooms across the country and 2) how to change the teaching methods so that they can place a greater focus on developing the learners' competencies and skills. (Hugh Delaney, 2019). 
Education has become an important tool in developing society, the people, and the nation. It is also the main mechanism for developing quality manpower and for assisting them to lead their lives happily with other people in the rapidly changing world of the 21 st century. Education plays an important role in creating a competitive advantage for a country and in allowing that country to stand firm on the world stage. Operating under dynamic economic and social systems, countries around the world hold to the importance and devotion to education as a way to improve their human resources in response to changes in the economic and social systems of there countries, regions, and the world and to maintain their national identities (Secretariat of the Council of Education, 2017).

The Constitution of the Kingdom of Thailand B.E. 2560 stipulates that education is an important tool for human development. The duty of the state is to manage all education, and that education must focus on learner development by empowering them to be good people with discipline, to have pride in the nation, to become a master according to his or her own expertise, and to be responsible for family, community, society, and the nation. This is consistent with the $12^{\text {th }}$ National Economic and Social Development Plan, which has as its main principle the adherence to the concept of "people as the center of development", aiming to create a good quality of life and well-being for the Thai people; to develop people, who are equipped with discipline, curiosity, knowledge, skills, creativity, good attitudes, social responsibility, ethics, and morals; and to develop people of all ages and to prepare them to enter the aging society with quality. The Plan also focuses on living within the environment in the support manner, which means that natural resources must be preserved, restored, and utilized appropriately in response to the vision under the 20-year national strategic plan to develop "Thailand to be stable, prosperous, sustainable, become a developed country grounded in the philosophy of Sufficiency Economy" (Office of the National Economic and Social Development Board, 2016).

In this study, the researcher examined and synthesized principles, concepts, theories, and researcher on Vocational Education Management from the Office of the Vocational Education Commission; Chatchai Ketprom (2010); Office of Vocational Education Commission (2008), and Laurent Filliettaz (2011). From these investigations, the researcher discovered the following 5 main elements of Vocational Education Management for the Community Colleges of the Northeastern Group under the Office of the Vocational Education Commission:

1) Participatory Management. It means carrying out Vocational Education Management by performing duties and/or working together with others or by creating opportunities for people, who work together, to express opinions, to make joint decisions about operations, to follow-up on and evaluate the work, and to receive mutual benefit in managing the quality of Vocational Education.

2) Curriculum Development. This means creating a new curriculum or making improvements to an existing curriculum so that it can be consistent with the changing world. Given that economic systems, society, and politics are all a part of mass experience; social development, which is in accordance with an individual's aptitude and the individual differences in personal interests, should be provided as life-long learning. In order that students are able to apply the knowledge they have acquired to prevent and solve problems and that they are able to cultivate morals, ethics, and good values; Curriculum Development should focus on teaching academic skills, analytical thinking skills, and professional skills through learning and practicing from real experience.

3) Systems Development Management. It refers to the management or adjustment of the administrative operational processes with respect to the departments and their personnel members, as well as to holistic management that is utilized to enhance the efficiency and quality of vocational education colleges, to empower learners, to meet the community's needs, and to be responsive to continuous changes.

4) Teacher and Personnel Development. This refers to the processes or procedures for increasing the knowledge, skills, expertise, and the experience of the teachers and personnel in Vocational Education Management. The attitudes of these personnel toward the jobs that they are in charge of developing need to be positive. Moreover, in order to carry out operations that meet the goals of the organization and that contribute to organizational efficiency and effectiveness, teachers and personnel need to be empowered to reach their utmost potential.

5) Collaboration Establishment. It means the Management of Vocational Education resulting from the cooperation between the vocational institutions and the workplace. In matters of cooperation between the areas of professional and educational management for the development of manpower at the semi-skilled level, the skilled level, and at the level of specific professional expert, there is the need to be responsive to the labor markets and with the conditions of the economy, society, the culture, technology and the environment. Learners need to be able to perform as practitioners, supervisors, or even entrepreneurs. Moreover, they need to able to be self-employed by learning through problem solving and constructing professional knowledge, as well as being of good personality, being moral, and having a appropriate attitude. 
Within a wide and borderless society, the business world is rapidly changing. With economic and political uncertainly, natural disasters, and intensifying competition, organizations need to strengthen themselves in order to prepare for the day-to-day activities. Therefore, small and medium enterprises (SMEs) cannot avoid facing all of the challenges that are likely to happen concurrently. As a result, there is an emergence of Start-up businesses. The concept is to create a new business challenge for a new generation of entrepreneurs, who want to survive from starting a business with a small amount of capital, but wanting to make good profits in a new generation of customers. This contributes to a new generation of businessmen and businesswomen between the ages of $20-30$ years old, who are attempting to own their own businesses. Therefore, a well-rounded preparation process, such as utilizing new work procedures, creating innovative products and services, and making adjustments to modern businesses, with a new generation of customers, and with technological advancements, is required. These are crucial elements required to be able to successfully gain advantages when beginning a start-up business. According to Cumming \& Worley (2008), it was found that young entrepreneurs had coped with rapid changes in technology and highly-negotiable marketing power, which had contributed to the survival of only $20 \%$ of businesses. Consequently, many organizations tend to pay more attention to the causes of failure or the factors of success as a part of new entrepreneurial characteristics, which should be developed along with generating income. According to the studies, in the event of a business crisis, most entrepreneurs often focus on changing the abilities and capabilities of their personnel and their organizational structure and making these their top priority. Regardless of the changing characteristics of entrepreneurs, they are leaders, who build trustworthiness. It is widely known that the characteristics of the image of 'good leadership' can support start-up businesses and can attract investors to participate in the businesses both through 'face to face communication' and 'real-time communication' through online media. This is especially true for start-up businesses because good leadership will have a positive effect on the health and wealth of the businesses and their regional development. Many entrepreneurs intend to make their business grow, and some want their businesses to grow rapidly. Thailand has many small and medium-sized enterprises, and these comprises millions of businesses, which make the economic wheels move forward and increase more domestic demand. This results in increases in domestic spending, which distributes the national economic base all across the country. Small and medium enterprises play an important role in driving the country's economy (Wannee Chonnaphasathit, 2009).

The Thai Vocational Education System has been ignored for so long that it has suffered from being of poor quality and has had image problems. These conditions have caused serious problems for all parties involved. For example, many vocational students lack good career opportunities because they have received low-quality educations. Therefore, when compared to those students with Bachelor's degrees, vocational graduates will make less progress in their occupations compared to the those graduates. As a result, students of low income families, who mostly encourage their children to study vocational education, actually have fewer opportunities to improve their family's social status. This phenomenon may result in two problems: 1) the overall education system may have higher costs because the cost per unit of a higher education is more expensive than that of a vocational education, and 2) overall, the investment in education provides lower returns because the education systems of universities often emphasize academic knowledge, which is less useful when the graduates do not have highly professional jobs that require the knowledge they have learned (Nattasit Rakiatwong,2018).

\section{The Research Objectives were as Follows}

1) To study the current conditions, the desired conditions, and needs assessment for management in order to enhance the entrepreneurship of students, who are enrolled in Industrial and Community Colleges of the Northeastern Group under the Office of the Vocational Education Commission.

2) To develop management strategies that can enhance the entrepreneurship of students in the stated colleges.

\section{The Research Methods}

The mixed - methods research was applied with 4 steps.

Step 1: The relevant documents and related research studies were examined to determine the research framework.

Step 2: The current conditions, the desired conditions, and the needs assessment for management to enhance entrepreneurship of the vocational education students were investigated. In order to enhance the entrepreneurship of students in the above - stated colleges, the priority of needs and index (PNI Modified) was applied SWOT analysis to find the strengths, weaknesses, and opportunities, as well as the obstacles facing management. 
Step 3: Management strategies for enhancing the entrepreneurship of students were drafted through conducting focus group discussions, the appropriateness of the management strategies were reviewed and recommended.

Step 4: Evaluation of Management Strategies were executed by all stakeholders before they were revised and completed.

\section{Research Results}

Regarding the current conditions of management, overall, were found to be at a "High" level. With regard to each and individual aspects, it was found that the aspect with the highest mean was Curriculum Development, followed by Collaboration Establishment, and Teacher Development, respectively. In contrast, the aspect that had shown the lowest mean score was the Characteristics of the Entrepreneurs. Regarding the desired conditions of the management required to enhance the entrepreneurship of students, all was at the "Highest" level. With respect to each and individual aspects, the aspect with the "Highest" average value was Collaboration Establishment, followed by Entrepreneur Incubation Center Management and the Characteristics of the Entrepreneurs, respectively. Conversely, the lowest average value was Curriculum Development. On the analysis of the conditions of management to enhance the entrepreneurship of students, it was found in all that the aspects that required a "High" level of necessity was the Characteristics of the Entrepreneurs (PNI Modified $=.353$ ), followed by the Entrepreneur Incubation Center Management $(\mathrm{PNI}$ Modified $=.350)$, and Teacher Development $(\mathrm{PNI}$ Modified $=.304)$. They were all the weakness of the conditions of Management that were needed to enhance the entrepreneurship of students. On the other hand, the aspects which required a low level of necessity was Collaboration Establishment (PNI Modified $=.250$ ), followed by Curriculum Development (PNI Modified $=.185$ ). They were the strengths of the management conditions, which were required to enhance the entrepreneurship of the students.

Management strategies for enhancing the entrepreneurship of students, who are enrolled in the stated Colleges comprised 9 strategies. Strategy 1: Promoting the use of innovation, creativity, and skills development for commercial potential, consisting of 4 measures and 4 indicators; Strategy 2: Promoting creativity, big dreams with clear visions, and critical thinking, with 9 measures and 9 indicators; Strategy 3: Realizing that change is a challenge and opportunity to test the ability in building a successful business, comprising 1 measure and 1 indicator; Strategy 4: Promoting a new generation of entrepreneurs in start-up businesses, with 9 measures and 10 indicators; Strategy 5: Developing the process of 'Entrepreneurial Incubation' through the SME business operations of Vocational Education,, with 9 measures and 10 indicators; Strategy 6: Promoting teachers to continuously arrange filed trips study and to participate in entrepreneurial business trainings, with 9 measures and 10 indicators; Strategy 7: Strengthening personnel skills to meet the standards for professional Vocational Education Development with 7 measures and 7 indicators; Strategy 8: Promoting and supporting educational institutes to provide bilateral education, with 6 measures and 7 indicators; and Strategy 9: Reforming the entrepreneurial professional curriculum via a bilateral education system, with 8 measures and 9 indicators. The evaluation of management strategies for enhancing the entrepreneurship of the students is essential.

According to the results of the evaluation on Management Strategies for enhancing the entrepreneurship of students, 60 stakeholders, who were been involved in Vocational Education Management, evaluated appropriateness, feasibility and utility based on the concept of Owens (1993) and on suggestions from experts on strategies related to the design for strategy evaluation. On the whole, it was found that all aspects were at the "Highest" level. Considering each and individual aspect, it was found that Appropriateness was at the "Highest" level, Feasibility was at the "Highest" level, and utility were also at the highest level.

\section{Discussion}

According to the development results of management strategies for enhancing the entrepreneurship of students the following were the important issues for discussion:

Overall, the present condition of the management for enhancing the entrepreneurship of students was found to be at a "High" level, considering each and individual aspect, Curriculum Development was of the "Highest" value, followed by Cooperation Establishment and Teacher Development, respectively, The desired condition of the management for enhancing the entrepreneurship of students was in all at the "Highest" level. Considering each and individual aspects, the aspect with the "Highest" value was Cooperation Establishment, followed by Entrepreneurial Incubation Center Management and the Characteristics of the Entrepreneurs, respectively. This can be interpreted that because the colleges had shown that their current condition was consistent with the desired condition. This indicated that they had complied with the policies of the Vocational Education Commission of the Ministry of 
Education. These are urgent policies for vocational schools, institutions, and establishments, for state enterprises, or for government agencies, which focus upon managing the educational curricula, the assessments, and the evaluations. In order to benefit the production and development of manpower, students are able to take some lessons at vocational education institutions and then take practical learning in the organizations of state enterprises or government agencies. Vocational education colleges or institutions can manage a variety of teaching methods at the same time. Most importantly the Colleges must focus on bilateral education management, which is consistent with the research results by Chakrapan Panchasuwan (2004), who examined a process for systematic problem solving in Vocational Education Management through a bilateral system of vocational colleges under the Office of the Vocational Education Commission. The study revealed that problem-solving in the workplace should start by having a mutual understanding between the entrepreneur and the vocational college with regard to the principles of managing bilateral vocational education and that the curriculum should be clarified. The organizing body should provide the same welfare for students as it provides for the establishment's employees. Information should be provided in terms of guiding educational institutes in the organizing orientation trainings, which is in congruence with findings of a study by Luechai Kaewsuk (2011), who investigated the development of the management strategies of Vocational Institutes in response to manpower demands of the establishment. The research results revealed the following: 1) The current conditions of the management of the Vocational Education institutes regarding the implementation of the Manpower Production Plan indicates that in light of the evaluation results, Manpower Production planning needed to be improved. According to a survey on production and work after graduation, it was found that the educational institutes would be able to produce the amount of manpower as planned. 2) With respect to the conditions of the workforce needs of the establishment, it was found that technical skills in specific majors were badly needed.

Regarding appropriateness, feasibility, and utility, it was found that the management strategies for enhancing the entrepreneurship of students were found, in general, to be appropriate feasible and useful. In addition, the management strategies could be put into practice to achieve real success at the "Highest" level. These finding confirmed that the Management Strategies for enhancing the entrepreneurship of students were appropriate and feasible and could be used to garner real benefits in alignment with the bilateral vocational education management practices of the Office of the Vocational Education Commission, as well as in response to the National Education Act 1999 and the Vocational Education Act 2008. Moreover, the management strategies corresponded with the results from a study by Lueachai Kaewsuk (2011), who examined the development of vocational education institution management strategies to meet the workforce needs of the establishment. The study revealed that the school management strategies, which were required to meet the needs of the workforce of the establishment consisted of 3 main strategies, 9 sub- strategies, and 19 measures. Furthermore, the strategies of promoting the use of innovation for creativity; of focusing on developing skills for commercial potential; of developing big dreams, broad visions, and critical thinking; and the strategies of witnessing changes and perceiving them as opportunities to achieve business abilities had helped to motivate learners and to empower them to search for opportunities. Moreover, these strategies assisted them in applying creativity so that they could make a difference in their business operations, develop a stronger sense of determination to establish and to continuously run a business, take the opportunities that are available in the market, and become involved in the procurement of resources and their utilization.Meanwhile, those entrepreneurs bore the risk while searching for opportunities and fostering creativity and innovation. The strategies, which are promoting a new generation of entrepreneurs in start-up businesses and the strategies that developed the 'Entrepreneurial Incubation Process' through the business operations involved with the project of SME Vocational Education, was pro-active strategies that helped to reduce weaknesses in management and have enhanced the entrepreneurship of students enrolled in the Industrial and Community Education Colleges of the Northeastern group as cited by Pranee Tanprayoon (2012) and Chaiyut Lertpachin (2011).

\section{Suggestions}

1) Since the findings from this study have shown that SME's are businesses that strengthen the national economy, further qualitative research studies should be conducted on successful SME entrepreneurs. More research should be carried out with the aim of uncovering the guidelines and factors that the entrepreneurs utilize in making their businesses successful.

2) Recommendation for further research should be conducted on other issues related to start-up entrepreneurs. This research has mainly focused on the development of start-up entrepreneurs. However, with respect to the success of entrepreneurs, other important issues should also be included, such as creating suitable environments related to the political, social, and technological surroundings; employing the innovative talents of the entrepreneurs; creating 
start-up businesses with organizational good governance; having models for businesses that originate with only small investments and then gradually expand to become large organizations (Small but Beautiful); fostering professionalism (Work like a Professional), and other elements. In essence, all of these factors affect the success of start-up entrepreneurs.

\section{References}

Chaiyut, L. (2011). Entrepreneurship. Copy document. Lampang: Faculty of Management Science, Lampang Rajabhat University.

Chakrapan, P. (2004). Systematic problem solving of vocational education management bilateral system of vocational schools under the Office of the Vocational Education Commission. Ph.D. Thesis (Vocational) Department of Vocational Education Faculty of Liberal Arts, Kasetsart University.

Chatchai, K. (2010). Development of a model to drive the philosophy of sufficiency economy to educational management of the College of Agriculture and Technology. Under the Office of Vocational Education Commission of the Northeast. Doctor of Philosophy Thesis in Educational Administration, Northeastern University.

Cumming \& Worley. (2008). Organization Development and Change (8th ed.). Ohio: Thomson South-Western.

Hugh, D. (2019). Education for the 21st Century placing skills development at the heart of education. Retrieved 2 January, 2020 from https://www.unicef.org/thailand/th/stories/Education for 21st-21st century

Laurent, F. (2011). Pedagogical aspects of initial vocational training in the context of the Swiss VET system. Journal of Vocational Education and Training, 09/2011.

Lueachai, K. (2011). The development of strategies for vocational education institution management to meet the needs Manpower of the establishment. Doctor of Thesis Chulalongkorn University.

Nattasit, R. (2018). Vocational education reform in Thailand. Retrieved 13 January, 2020 from https://tdri.or.th/wp-content/uploads/2016/08/nuthasid-vocational-education-v02_2.pdf

Office of the National Economic and Social Development Board (2016). Summary of material points of the National Economic and Social Development Plan Twelve editions 2017-2021. Bangkok: Office of the National Economic and Social Development Board. Office of the Prime Minister.

Office of Vocational Education Commission (2008). Vocational Education Act 2008. Bangkok: Ministry of Education.

Owen, J. M. (1993). Program Evaluation: Forms and Approaches. j.m. owen, p.j. rogers; international edition, sage, london, 1999, 312 pages, hardcover, isbn 0-761-96177-1. Evaluation \& Program Planning.

Pranee, T. (2012). Characteristics of Entrepreneurs and Entrepreneurs Success in Small and medium enterprises in Phra Nakhon Si Ayutthaya province. Phra Nakhon Si Ayutthaya: Phra Nakhon Si Ayutthaya Rajabhat University.

Pressman, J. L., \& A. Widavsky. (1973). Implementation. Berkely, California: University of California Press. Ltd.

Secretariat of the Council of Education. (2017). National Education Plan 2017-2036. Bangkok: Ministry of Education.

Wannee, C. (2009). Study factors enhancing sustainable success of dessert business operation in Phetchaburi province. Modern Management Journal, 7(2), July-December. Retrieved from https://so04.tci-thaijo.org/index.php/stou-sms-pr/article/view/11830

\section{Copyrights}

Copyright for this article is retained by the author(s), with first publication rights granted to the journal.

This is an open-access article distributed under the terms and conditions of the Creative Commons Attribution license (http://creativecommons.org/licenses/by/4.0/). 